\title{
Correction: Exploring pre-surgery and post-surgery substance use disorder and alcohol use disorder in bariatric surgery: a qualitative scoping review
}

\author{
S. Kanji ${ }^{1}$ E. Wong ${ }^{1} \cdot$ L. Akioyamen ${ }^{1} \cdot$ O. Melamed ${ }^{1} \cdot$ V. H. Taylor ${ }^{1,2}$
}

Published online: 11 September 2019

(c) The Author(s), under exclusive licence to Springer Nature Limited 2019

Correction: International Journal of Obesity

https://doi.org/10.1038/s41366-019-0397-x
In the original Article, Leo Akioyamen's surname was misspelled as "Aikiyomen." This has been updated in the XML, PDF and HTML versions of this Article.

V. H. Taylor

valerie.taylor@wchospital.ca

1 Women's College Research Institute, Toronto, ON, Canada

2 University of Toronto, Toronto, ON, Canada 